\title{
An analysis of future orientation and some of its social determinants
}

Gisela Trommsdorff \& Helmut Lamm 
An Analysis of Future Orientation and Some of its Social

Determinants

G. TROMMSDORFF AND H. LAMM

\section{INTRODUCTION}

\section{Time and the Experience of the Future}

Time will be understood here from an internal point of view, that is, as a person's subjective experience. The psychological experience of time contains the experience of the past, the present and the future. This experience can be cognitively represented in the mind of a person; thus, cognitive abilities and intellectual training would be relevant for the way a person conceives of time. Furthermore, the motivational structure of a person determines the experience of time to some extent; past, present and future contain events which are more or less desirable for a person. Hence, the motivational tendency. to approach or to avoid specific events is relevant for a person's psychological experience of the future.

A person's experience of the future will be analysed in terms of his image of the future, that is, what he expects the future to be like, what events he would like to occur in the future and what events he rather fears.

Future orientation will be analysed here as a set of subjective expectations and beliefs held by a person about his future. The future includes positive and negative goals which a person believes he may attain or rather avoid, and the expectation of positive or negative actions of others. Thus, experience of the future implies a goal-related structuring of time, judgments and evaluations of future problems, and planning for possible future behavior.

Since we view human beings as "social animals", and since experience of the future is understood here as a psychological process which has been learned in specific social settings, we assume different ways of future orientation, for persons from different social groups.

Future Time Perspective

People's experience of the future has partly been studied in the literature under the label of "future time perspective". In these studies mainly cognitive variables were taken into account while the analy-

*This study was supported by the Deutsche Forschungsgemeinschaft and was conducted in

the Sonderforschungsbereich 24, Universität Mannheim. We wish to thank Siegfried Streufert for his valuable comments on the manuscript. We also thank Rolf Werner Schmidt and Henning Eckel for the ideas they contributed to this paper. sis of affective and evaluative components was largely neglected. Future time perspective also has primarily been treated as a unidimensional variable which could either be measured by its structure or by its extension into the future (Barabar 1970; LeShan 1952; Tehan 1958; Wallace 1956). Sone authors have defined structure in terms of the density or frequency of coocens (the number of future events mentioned by the subject) (e.g., Kastenbaum 1961). Wallace (1956) measured structure as the coherence of time ordering of events. He thus stressed the aspect of consistently ordering several events into a time sequence. However, neither the content of the events and their order in terms of sequence of preconditions and consequences, nor the duration and the relative importance of the future events for the person were taken into account by this method. It was assumed that a coheren ordering of future events - in terms of when they occurred - is an indicator for a person's logical structuring of the future. Coherence, as measured by Wallace (1956), is the correlation coefficient between subjects' indication of how old they would be when certain future events occurred (one variable) and the ordering of the same future events into a sequence of time (second variable). This method seems to replace one variable for another rather than account for the coherence of future time perspective in terms of its potentially multidimensional basis.

Beside the frequency of concerns and the coherence of future time aspects, the extension of future time perspective was measured in several studies. Wallace (1956) defined extension as "length of future time span which is conceptualized" (Wallace 1956, p. 240) and as " . the range of years included between subject's actual age and the most distant event given by him” (1956, p. 241).

There have been numerous studies on future time perspective using the "classical methods" of measuring the variety, coherence, or extension of the future but neglecting other important variables which theoretically account for further relevant cognitive aspects of future time perspective such as logical and time structuring judgment of probabilities of occurrence, and the evaluative assessment of future events.

In the following, an attempt will be made to discuss people's experience of the future including various relevant cognitive and evaluative variables which so far have rarely been taken into account in the analysis of future time perspective and have not yet been integrated as dimensions of the psychological experience of the future.

\section{ANALYSIS OF FUTURE ORIENTATION}

The term "future orientation" ( $\mathrm{FO}$ ) rather than future time perspective will be used here systematically to investigate what people experience when focussing their attention on the future.

Future orientation thus will broadly be understood here in terms of a person's expectations and concerns - his hopes and fears - which will be analysed through cognitive, evaluative and affective concepts.

Cognitive Aspects

Logic. Persons may anticipate the future as a complex of events ${ }^{1}-$ distinguishable entities - occurring in a process of change. The future may be structured as a set of more or less logically interrelated 
Affective and Evaluative Aspects

A person's attitude toward the future may contain positive and negative feelings. The uncertainty implied by the future and the expectation of dissatisfying future events may support negative feeling toward the future for some persons, while other persons may view the uncertainty rather as a challenge or expect rewarding events to occur (affective aspect).

An analysis of evaluative aspects focuses on the relative rewards and costs of future events. Certain future events relate to preconditions, which are rather costly for the person while the consequences are rather rewarding. Hence, the relative weight of preconditions and consequences in relation to future events should be taken into consideration as another factor influencing the cognitive work of structuring the future. Assuming too costly preconditions for attaining a desirable future event, the person may rather re-structure his future and envisage another desirable future event with less costly preconditions.

Content of future-related concerns. Hopes and fears are related to different needs and motivations of people. Hence, one cannot analyse FO independently of the content of the future-related concerns (although future time perspective has mostly been viewed under the structural aspect and as a contentirrelevant variable). The investigator of FO should take into account the meaning and relative importance of people's future related concerns and study the values underlying people's different hopes and fears.

If the personal future has a different meaning to people than the future of public life, one can expect that people have different FO's relating to different kinds of future events. ${ }^{2}$ Hence, logical structuring, expected occurrence and duration of events, and extension into the future will be different depending on the kind of people's future-related concerns.

Maximization of rewards in the future. Persons evaluate future events in terms of their relative rewards and costs. Persons structuring their FO "rationally" would follow the rule of maximizing expected rewards and minimizing expected costs in the future. Insko \& Schopler (1972) distinguish between three types of psychological hedonism: hedonism of the past, hedonism of the present and hedonism. of the future. "The distinction among these three types of hedonism is necessitated by the fact that responses which maximized reward in the present may not be responses which maximized reward in the past or will maximize reward in the future" (p. 32). Hedonism of the future would be an attempt of the individual to maximize the expected reward of events and minimize the expected occurrence of unpleasant events in the future - a requirement of rational planning and future-orientated decision making. ${ }^{3}$ This attempt may imply a great deal of cognitive work on the part of the individual. The person has to look ahead, collect information on possible decision alternatives and their potential consequences with respect to his present situation, and relate the overall rewards and costs of his different behavioral alternatives to the desired future state.

"Irrational" processes influencing FO. Future-orientated decision making and the structure of FO which is guided by hedonism of the future will be referred to as "future-oriented rationality".

The "rational" structuring of future events could be disrupted by primarily considering rewarding preconditions and consequences of desirable future events instead of taking into account the negative or future events. A logical ordering of the future may focus on preconditions as well as on consequences which are precisely defined and coherently ordered into a consistent system of interrelated events. proble future probably takes place in relation to those future events for which a rather general agreement exists as to how they can be attained or be avoided (preconditions) and what they are likely to entail (consequences) (e.g., educational requirements for attaining a specific job which in turn offers a certain amount of income and prestige). Planning for the future probably depends to some degree on a logically structured FO.

It would be interesting to study the amount of coherent (logical) future structuring relative to a complex but rather incoherent and non-integrated view of the future. Studies on cognitive complexity (see Streufert 1970) would be helpful for a further analysis of this problem.

Occurrence, duration. The structure of FO may also be analysed in terms of when the expected events will occur and how long they may last. The expected occurrence and duration of future events is closely related to the logical sequence of preconditions and consequences (see above). An education which is broken off before the required time (duration, occurrence) will not be a sufficient basis (precondition) for attaining a good job (hope) and thus makes the person renounce the consumption of some desirable goods (consequences).

Extension (time span). Another cognitive aspect is the time span a person takes into account with regard to his future. Beside considering when the future events will occur and how long they will last, a person has to think considering when the future events will occur and how long they will last, a ger the time perspective is extended into the future, the more consequences of future events could theoretically be taken into account for adequately structuring one's future. A long extension of the future, however, does not necessarily mean that more future events and consequences are taken into consideration than in a shorter extension of the muture orientaton. The future events may be of different duration and thus detrinine the total time span of a person. It may be more realistic to have a short FO - depending on the kind of future events taken into account. In some respects the FO of older people necessarily is shorter than that of younger people.

Variety. Structuring and - possibly because of learning experiences - re-structuring one's future in accord with one's values and beliefs implies the cognitive ability to process information concerning a variety of concerns. Thus, a sufficient variety of future events (see footnote 1) should be taken into account in order to structure one's future adequately. It is therefore important to measure the number of different kinds of future events taken into consideration by a person. Some persons will envisage future events (hopes and fears) which belong to the same category of events (e.g., several ob-related concerns); others will envisage the same number of events but each constituting a differen kind of future-related concern. (Incidentally, it is problematic to assume that a specific category of event - as defined by the investigator - has the same meaning for different persons.)

As stated above, extension and variety of FO are different aspects and should be treated as variables which may correlate only under certain circumstances.

Probability judgments. A basic requirement for structuring one's future is to assess the expected probabilities of occurrence of the future events. Persons may estimate the probability in terms of their certainty as to whether the events will occur. Time (near or far future) and extension (short/long) may also be the focus of probability estimations. 
costly preconditions and consequences. For example, a desirable future event, such as marriage, may be followed by costly behaviors, such as giving up some freedom and investing time and energy for maintaining the partnership. A "rational" structuring of the future would take into account all influential causes and consequences of an event, not distorted by their evaluative character

The occurrence and duration of future events may also be judged non-rationally. Events which are expected to occur in the far future may have a different motivational impact on structuring the future than events which will occur very soon; furthermore, the motivational impact will depend on the relative negative or positive value of these future events. ${ }^{4}$

Expecting to retire and to have less money in the far future may induce people to save some money and attain other forms of economic security in the meantime - a case of rational planning. Equally familiar is an example of an irrational case: A heavy smoker may expect to get cancer some time from now if continuing to smoke. However, since the negative future event is rather distant in time, the smoker may tell himself to continue smoking for a little while and to stop sometime in the future. Both events, getting cancer and stopping smoking, are not fixed in a time schedule of FO and thus Both events, getting cancer and stopping smoking, are not fixed in a time schedule of FO and thus
may be used for psychological defenses. The dissonance experienced by the future threat and the may be used for psychological defenses. The dissonance experienced by the future threat and the
present reward is reduced by the vagueness of the time schedule lying between now and the far future.

Irrational structuring of the future may also result from the expectancy of a threatening event in the very near future. This closer threat may prevent the person from rationally structuring the time following this event. This case often arises in crisis situations when people panic.

Similarly, the motivational impact on a person's time span extended into the future may have irrational effects. Persons expecting negative events like sickness and economic crisis in the far future may prevent themselves from thinking this far ahead and rather extend their time perspective into the near, more rewarding future. On the other hand, a dissatisfying present and the expectancy of a costly near future may stimulate persons to hope for rewarding events in the far future and thus extend their time perspective far ahead - too far to rationally decide on how probable those desirable future events (e.g., a revolution or the rebirth of the savior) are.

The variety of possibilities seen for one's future may be restricted by avoiding to envisage potentially costly and/or threatening future events. It can be assumed that a greater variety of future events is seen when these events are desirable, if it is supposed that people prefer to think about desirable, as compared to undesirable, events.

Finally, the probability estimate may be distorted because of motivational factors. A highly undesirable future event may be viewed as less likely, while a highly desirable event may be viewed as more likely (tendency for "wishful thinking", see McGuire 1968). ${ }^{5}$ Persons with a negative attitude toward the future would tend to expect primarily negative events to occur in the future.

Cognitive, Affective and Evaluative Aspects of FO: Optimism/Pessimism

Optimism/pessimism is a largely neglected variable in the study of FO. Vaughn and Knapp (1965) considered optimism/pessimism as a personality variable.
Evaluative probability estimates. Optimism/pessimism may be defined in terms of the judgment people make about the probability of occurrence concerning the timing and duration of future events. An optimist - in contrast to a pessimist - would expect a desirable event to occur in the near future and would expect it to have a long duration. Likewise, an optimist would judge rewarding events to occur with high probability, and costly events with low probability. Though a pessimist's probability judgments may be symmetric to those of an optimist, the motivational background of these judgments may be different. Wishful thinking tendencies would stimulate some people to make unrealistically optimistic judgments. Unrealistically pessimistic judgments may result from uncertainty and insecurity. Some people underestimate in order to prevent too high expectations of other people. An insecure Some people underestimate in order to prevent too high expectations of other people. An insecure
student would rather tell his parents he will fail; in case he really fails, the parents may not punish him severely since they have already lowered their expectation level; if he does not fail, his parents will be delighted and reward him possibly more than if he had not made such a pessimistic judgment.

Hedonistic learning experience. Cantril (1965) and Galtung (1970) conceived of optimism/pessimism as an important variable of people's concerns about the future. They measured optimism in terms of where a person places himself on a self-anchoring scale indicating his best and his worst possible life at the present time, five years ago, and 5 years from now: The distance from the point where a person at the present time, five years ago, and 5 years from now: The distance from the point where a person
places himself in the present to the point where he expects to stand in the future, served as an indicator for optimism/pessimism

If the expectation of future events is seen on a dimension of maximizing one's satisfaction (hedonism of the future), it makes sense to define optimism as being present when the expected outcomes of future events are judged to be greater than the outcomes of past and present experiences; a pessimistic judgment would be given if future outcomes are judged to lie below this comparison level of past and judgment would be given if future outcomes are judged to lie below this comparison level of past and
present outcomes. Optimism/pessimism thus can be defined as the discrepancy between the expected outcomes and the actual future outcomes. (A person's subjective experience of the present and expectation of the future are the basis of this measurement of optimism/pessimism.)

One may assume that other structural aspects of FO such as time extension can influence optimism/ pessimism. Conversely, an optimistic view of the future can stimulate a person to extend his time perspective more into the future since rewarding outcomes are expected.

Optimism was defined so far (a) as evaluative probability estimation concerning the occurrence, time and duration of future events, and (b) as the perceived discrepancy between past and present outcomes and expected future outcomes (distance from comparison level of present standing). The first definition depends on the expected reward and cost of the future event; the second definition depends on the relation between how the present is perceived and what is expected from the future in terms of maximizing one's satisfaction (hedonism of the future). Both definitions implicitly take into account people's beliefs about who controls future outcomes, as will be discussed later.

Behavioral Aspects of FO

Mainly from studies on attitudes (see Abelson et al. 1968) one can expect the attitudinal component of FO to have some behavioral implications. FO also can determine decision making and behavior due to a person's motivation to achieve some future goals and try to avoid certain other fear-inducing 
future events (see Heckhausen 1967). Decision making and behavior partly depend on a person's belief in his own abilities to master the future or, alternatively, his attribution of outcomes to other forces (see Weiner 1971), and on his adequate cognitive structuring of present and future. Present decisions are usually made on the basis of future outcomes. On the other hand, the present situation and past experience determine the setting of goals and the evaluation of possible future events. The kind of future events which people expect to occur, people's judgment of these events, and the people's choice can often be extrapolated from the present situation.

An important behavioral aspect of FO is a person's choice between immediately rewarding vs. later rewarding events. A person's ability to postpone immediate smaller rewards in exchange for later larger rewards may be predicted from the cognitive and evaluative character of his FO (see Mischel 1974).

Analytical Schemata of FO: Summary

Our intention is to point out that FO is a multidimensional complex. The cognitive dimension can be analysed in terms of structural variables such as logical ordering of future events, probability judgments concerning the expectation of occurrence, time and duration of future events, frequency, and variety of future events. The affective and evaluative dimension may be analysed in terms of the reward value of future events. An investigation of FO should focus on the different aspects of $\mathrm{FO}$ and how they relate to each other (e.g., estimation of probabilities as a cognitive variable and desirability of future events as an evaluative variable). ${ }^{6}$ It is not adequate to use one aspect of $\mathrm{FO}$ (such as future time extension) as an indicator for another aspect (such as variety) or for the whole complex of $\mathrm{FO}_{7}^{7}$ The dimensions of FO and the relationship between any of the variables of FO may not be the same (a) with respect to any kind of future-oriented concerns, and (b) for all persons.

In the following, the general analysis of FO as described so far will be treated with respect to several factors which are așsumed to account for individual differences among people on the various dimensions of FO.

\section{SOCIAL DETERMINANTS OF FUTURE ORIENTATION}

Theoretical Background and Derivation of Hypothesis

One may assume that $\mathrm{FO}$ is determined by social learning experience which probably is not the same for everyone but similar for persons with the same life style, background, traditions, values and childrearing experiences - for persons belonging to the same social groups.

Social variables, such as status and role, are rather complex, but may be used for grouping people into some broad categories which take into account differences in cognitive development, learning and motivation. Social status.partly accounts for a specific learning experience affecting the cognitive, evaluative and affective style of a person. Social roles determine people's expectations and behavior to some degree so that this variable may be used also to predict differences on various aspects of FO. In the following, we will only analyse the influence of low and high social status on FO and select age and sex as bio-social roles to study their relative impact on people's FO, that is, on the cognitive, affective and evaluative aspects of FO.
Derivation of Hypotheses

Future orientation can partly be seen as goal-related structuring of the future and planning for possible future behavior. Achievement motivation, as has been shown, is related to a person's assessment of future events, that is, to hopes and fears he wants to attain or to avoid (see Doob, 1971 ; Heckhausen 1967; Knapp \& Garbutt 1965; Weiner 1971). Thus, some of the theoretical considerations from studies on the impact of social class and socialization experience on achievement motivation may be invoked for generating hypotheses about social determinants of FO.

On the other hand, FO can be seen mainly as a cognitive variable. Research dealing with the impact o social variables on cognitive abilities and cognitive development (see Kagan \& Kogan 1970; Frohlich 1972) could be used here to derive some hypotheses concerning the social determinants of FO.

Cognitive aspects. Cognitive abilities - such as complexity - are assumed to be partly dependent on the development and learning stage of the individuum. These in turn are presumably influenced by social status (e.g., education level) and by bio-social factors such as age (the time and length of learning experience) and sex (the socialized role).

Impact of social status. It seems rather obvious to assume a better cognitive learning experience for persons of high than for persons of low social status. Studies on cognitive abilities of persons from different social status have pointed out that the verbal code, the ability for abstraction, differentiation and long-term planning is better developed in middle than in low status people (see Oeverman 1969).

A relation of present social standing and future time perspective ${ }^{8}$ has been demonstrated by Teahan's (1958) finding: Children who had more success in school thought more about the future and had wider temporal perspectives than children at the bottom of the class. However, the question remains whether this effect is due to the influence of social status since the data are correlational.

Schneider \& Lysgaard (1958) found that middle class children are more willing than working clas children to postpone a reward; they preferred to save a larger part of a fictitious winning. This greater capacity of middle class children to delay rewards may be attributed to their ability to look further into the future than lower class children, and may be related to high achievement motivation and the ability to tolerate frustration (see Mischel, 1974).

LeShan (1952) found that children from the middle class invented stories covering a larger period of time than working class children ${ }^{9}$ The author assumed that midde chas children are more oriented toward distant projects than working which they probably cannot attain. He thus explained the above finding by the class-related socialization experience of these children.

The line of reasoning for hypothesizing a relation between the cognitive dimension of FO and social status could be as follows. The socialization patterns of high status persons presumably induce a high need for achievement. High need for achievement implies high ability to postpone immediate reward (Mischel 1966). High capacity to delay gratifications requires an extended FO. ${ }^{10}$ This, a more extended FO can be expected for high status people rather than for low status people. Evidence for the assumed impact of variables like socialization experience on FO does not yet exist. Data indicating a 
possible relation between these variables are onlv correlational.

One could readily assume a better cognitive development for persons of high education than for persons of low educational level. To the extent that better cognitive development involves greater cognitive complexity, a greater variety of FO may be expected to accompany higher educational levels. A better cognitive education should strengthen the ability for abstraction and logical thinking. Thus, possible sequences of logically interrelated future events will presumably be viewed with greater precision and frequency by high than by lower class persons.

The presumably better cognitive development of higher class persons may also lead one to expect that their FO is more extended. The cognitive ability to envision a high variety of future events may induce a person to extend his time perspective and place these future events in a long-run sequence. Thus, leaving aside assumptions from research on achievement motivation, we may expect a more logica precise, consistent and coherent FO, greater variety, and a more extended FO11 for persons fron than for persons from low class - on the assumption of better cognitive education for higher than for lower class persons.

Assuming that people's FO consists of various aspects relating to a variety of future events, one should analyse the impact of social variables on the structure of FO in relation to the variety of interests, needs and values people have. High status persons are known to participate more in public affairs than low status persons (see Popitz 1968). Assuming that present concerns affect future-related concerns, one may expect a better to public concerns.

Impact of age. The learning experience of an adult will be greater than that of an adolescent. His ability to differentiate and his access to informition will be more developed than for adolescents. would be in line with this assumption to expect a more complex FO for adults as compared with adolescents.

The extension of time perspective into the future presumably is affected by the expectation of dramatic changes during life - the next following period of change in the near future will probably be of greatest concern, eventually followed by changes further away. Young people generally envisage more problematic events occurring in the near future than adults of 30-40 years old; a greater frequency of changes occurs in the life of adolescents, like finishing an education, getting a job, getting married, and becoming independent. These dramatic changes will probably occur in the near future of adolescents, while comparable drastic changes (such as illness, retirement etc.) for adults presumably occur only in the more extended future, like one decade or two from now. In this line of reasoning, one may assume that adolescents have a less extended time perspective than adults since more dramatic events may happen to them in the near future.

Impact of sex. A different cognitive orientation toward specific future events can by hypothesized for persons of different sex. Research on sex-role learning (Maccoby 1966; Myrdal \& Klein 1956) has shown that sex-typed behavior and interests are socialized since early childhood. Females are more oriented toward social-emotional (expressive) behaviors while males are more oriented toward instrumental roles. The traditional socialization experience directs the concens of females more toward family-related problems and the concerns of males more toward public problems (Trommsdorff 1968). Again, assuming an effect of present concerns on future-related concerns, females presumably envisage more private concerns than males.

Optimism/Pessimism

Belief in internal/external control. A generally optimistic view of the future may derive from trust in one's own abilities and from the belief in being able to master difficulties oneself ("internal control") as opposed to low trust in one's own abilities and the belief in external forces (other people; externa circumstances, fate) ("external control"). 12 would a person believing more in internal control be also efuture Core \& Rotter (1963) indicate a positive correlation between ber in external control and pessimism. A person believing more in exteral th in internal control of the future presumably has less concrete information as to how these external forces (like fate) work an what they will bring about. The less information a person has about how outcomes are affected, the more likely he probably is to make non-realistic ${ }^{13}$ judgments about the future, judgments which may be extremely optimistic or pessimistic.

Belief in internal/external control ${ }^{14}$ will be understood here as an intervening variable presumably accounting for differences in the extent of optimism/pessimism.

Why should some people be more optimistic or pessimistic ${ }^{15}$ than other people? Again, persons will be seen as members of social and biological groups, characterized by certain socio-psychological teatures. Social status and role again are analysed as determinants of FO.

Impact of social status. A person's setting of goals can be assumed to be related to his beliefs concerning the attainability of these goals. These beliefs probably are dependent on the given present situation and on the available information concerning possible future outcomes and how they are to be achieved. A relatively high standing in the present (and past) could affect a person's belief that his future standing will be at least as satisfying as now. One may thus hypothesize that high status people - who presumably enjoy a better social situation (and who also have more access to information on how to reach certain goals) - are more optimistic about their future than low status people are.

On the other hand, one may as well assume that low status people expect their relatively unsatisfying present standing to change into a more positive direction. Low status people have to lose less than high status people and may expect rather to win than to lose. They may thus be more optimistic than high status people expecting changes from their currently dissatisfying position into a desirable direction. Which of the two hypotheses about optimism and social status is correct must be tested by empirical data.

A relation between pessimistic expectancies, fatalism and low social status has been suggested by socilogists (Popitz 1968). One may assum that people of low status have less information - because of their lesser cognive developant - about how gols may be at hen ans how fears may be coun- 
events and the lack of past success in this respect may make these people more prone to believe in external forces. They may become resigned to their fate and rather leave things happening. However, the lack of information and the belief in external forces may induce unrealistic but not necessarily more pessimistic expectations - e.g., when wishful thinking tendencies work in the direction of optimism.

Social class probably also determines the kind of future-related concerns (hopes and fears) according to the values and goals people have. From the literature on social participation we know that people the values and goas pe of higher status participate more in public affaiss than people of lower status (Popitz 1968). Thus, a tor public concerns.

Impact of age. Assuming that young people have more possibilities ahead and have less experience and information about possible future outcomes than adults, a wishful thinking tendency resulting in high optimism could be expected for young people more than for adults. Adolescents, furthermore, are farther away than adults from negative aspects of the future, such as old aee, retirement, sickness and dethe all this may belp to disco the future concerns conceived of, adolescents may - on the pessimistic about their future than adults. The amount of change to be expected in the near future is greater, more crucial, and possibly less certain than for adults. The uncertainty in regard to highly important future events may be threatening to some people - presumably to those with low belief in their own abilities (and low self-esteem) - and may induce pessimistic judgments.

Impact of sex. Probably more negative future events are waiting for females than for males, such as the menopause and the loosening of family ties which are more important to females than to males (see Lehr 1968). One may thus expect females of a certain age to be more pessimistic about their near future than males.

\section{Empirical Evidence}

In the following, some findings of a recent study, conducted together with R.W. Schmidt and Henning Eckel (unpublished data ${ }^{16}$ Sonderforschungsbereich 24, Universitat Mannheim, 1973) will be repordescribed above was the basis of this study analysing the impact of social status and role on some of the relevant dimensions of FO.

We asked persons ${ }^{17}$ of low and high social status. ${ }^{18}$ to list their hopes and fears (open-ended question), to indicate their age when these future events will occur, and to indicate whether these events will depend on own abilities or on external forces (see footnote 1).

\section{Cognitive structure of $F O$.}

Impact of social status. Persons of high status named significantly 19 more concerns (hopes and fears) and had a greater number of different categories ${ }^{20}$ of concerns than persons of low status. They also had a more extended ${ }^{21}$ FO than low status persons. Thus, the FO of better educated persons is characterized by a larger number and a greater variety of concerns, and a longer time extension into the future than is the case for less educated persons.
Impact of age. No difference in the variety of future-related concerns was found between adolescents and adults. However, persons from these two age groups differed significantly in the distribution of their concerns to specific categories of future events. Adolescents named more private and fewer public hopes and fears than adults: More than $80 \%$ of adolescents' future-related concerns related to private events.

Impact of sex. Females were more concerned about family-related than about job-related problems as we had predicted. Adolescent males were more concerned about their job than about their family; adult males had about the same amount of concerns for family as for job-related problems.

Females were not only more concerned, they also had a more extended future time perspective, with regard to family-related than to job-related concerns. For males (with the exception of low status males who had a more extended FO with regard to job-related concerns), the family and job-related concerns were viewed with about the same future time extensions.

It is interesting to note that only adult females were equally interested as adolescents of both sexes in personal problems, such as private life, personal satisfaction and development of personality traits.

Conclusions. These results demonstrate the effect of status, age and sex (presumably determined by learning experience) on specific future-related concerns. If we had not differentiated FO as a set of various categories of concerns, we would not have found adolescents to differ from adults. Viewing tire (family, job and personal satisfaction) than concen life their future public life (economy, political development, environment). Adults, on the other hand, entertain the same number of future-related concerns for private and for public life. Adolescents may be more concerned about their future private life as long as they have not achieved stability (a completed education, a job, and marriage)

We also found a more individualistic $\mathrm{FO}$ for adult females and adolescents in contrast to a $\mathrm{FO}$ attached to public problems in adult males. Probably adult males believe they have solved their individual problems; having achieved a fair degree of private security, they now have room for shifting their interest to more public concerns.

A more structured $\mathrm{FO}^{22}$ for private than for public concerns in low status adolescents, and in female adults of both status, indicates a tendency to retreat from the complicated problems of public life and to get settled in a well structured private life.

It is necessary to view $\mathrm{FO}$ as comprising various variables. We should not extrapolate from the knowledge of one dimension to the total FO. The general prediction that better educated people have more structured and longer time perspective than less educated people was only partly supported. People in both status groups have about the same number and the same variety of concerns, with the exception of adolescents. People of higher education, however, have a more extended FO than people of lower education in all concerns.

Optimism/pessimism. ${ }^{23}$ Generally, people of high status were more optimistic than people of low status, but this was only true for adults. 
While low status females of both age groups were very optimistic, high status girls were rather pessimistic and had more fears than boys. Low status females and high status girls believed in external control of future outcomes. High status women (all of whom had a job) believed more than high status girls in internal than external control and were more optimistic.

Possibly, females (only high status ones in the case of girls) have been frequently discouraged in initiating and completing things on their own, and thus were encouraged to believe that future outcomes are rather controlled by external forces. While low stans females adopt a wishful the hing sul hinking tendency, high stus gils are extreet women are more optimistic than high status girls, possibly because of satisfying past attainments. The high status girls presumably have not had similarly encouraging experiences and thus they adopt more passive and pessimistic view of the future.

The (more or less implicit) assumption of sociologists that low class people believe in external contro and have a fatalistic outlook into the future (see Popitz 1968) could not be supported in our study for males. Other variables like sex should be taken into account when making assumptions about social status, belief in extemal control and pessimism.

\section{Concluding remarks.}

Differences in people's FO may be predicted partly from their social status and role. It seems probable that socialization experience for certain roles and cognitive development account for some of the variance in FO among people.

Socialization experiences in higher social class probably are related to the attainment of influence and to social responsibility; thus, more concerns for public events - compared with lower class persons are acquired. Socialization for public influence and responsibility, and the cognitive development which increases the ability to structure complex problems, may account for a more extended and better structured FO with respect to public events in high status adults.

Socialization experiences - in the way of passive, family-oriented and individualistic role patterns on the one hand and active role patterns oriented toward public concerns on the other hand - presumably account for the different future concerns of females and males.

If the expectation of a better future situation is based on a presently satisfying social situation which also gives enough avoided withou reason to believe that hopes could be realized and feared states of affairs could be situation, not offering adequate means for change by employing one's own abilities, gives a basis for belief in external control and extreme optimism (wishful thinking) or pessimism.

The focus of this paper was to investigate $\mathrm{FO}$ as a multidimensional variable, comprising cognitive, affective and evaluative components. The expectation and evaluation of the future has to be studied in relation to the concerns (hopes and fears) people have, that is, the various future events that may happen to them. Social variables may be used as indicators for specific social experiences determinin FO. Mediating variables - such as belief in internal versus external control - constitute addition determinants of people's optimism/pessimism.
The knowledge of a person's FO may help to predict his pattems of future behavior. Too little is known yet about the impact of FO on behavioral styles. One may assume that a clearly structured arrive at decisions which improve the quality of his future life. 
NOTES

1. In the following, future events or future related concerns are understood as distinct entities of the future which a person refers to as his hopes or fears or as an expected state of being in the future.

2. The meaning of private and public concerns for different people may not coincide with the investigator's categorization of concerns. Thus, for some people, family and public-life-related concerns lie at the extremes of the same dimension, while for other people these concerns inply different dimensions.

3. The classical models in decision theory are based on the assumption that probabilities and values are independent of each other (see Edwards 1962). For a discussion of conditions unde which the independence assumption does or does not hold, see Feather (1959) and Kogan \& Wallach (1966).

4. For example, an individual engages in wishful thinking when he expects the future occurrence of a desirable event that has an objectively smaller than $50 \%$ chance of occurrence, and whe he expects the respective state of attainment to last longer than is objectively likely.

5. Crandall, Soloman \& Kellaway (1955) and Irwin (1953) showed the same tendency for estimates in a chance context.

6. See optimism/pessimism as indicator for cognitive and evaluative aspects of FO.

7. Several studies on future time perspective use one variable, e.g., future time extension, as an indicator for future time perspective.

8. There are quite a few studies on time perspective and social class; however, they should be critically evaluated in the context of measurements used. For an overview see Doob (1971).

9. While Lessing (1968) confirmed these findings of LeShan (1952), Ellis et al. (1955) and Judson \& Tuttle (1966) could not find social class differences in future time extension of children.

10. Doob (1971) assumes the following relation between temporal motives and behavioral tendencies: "Gratification is likely to be deferred when the temporal orientation is toward the future and vice-versa," (p. 93). However, when the attainment of future rewards is doubted (pessimistic judgment), immediate gratifications are not likely to be postponed.

11. This description of FO only points to the cognitive style of the person - no predictions are made whether such a person behaves according to this style by rationally planning the future, responding in a flexible way to new information or coping with "his future" in a relistic nenrigid way. The actul implementation of a peron's phos may involve departures from his orginal FO and this in turn, may induce him to chen he his behavior accordingly (see "concomitant change" in Doob 1971, p. 403 ff
12. We thus use the term internal/external control somewhat differently from Rotter (1966).

13. Non-realistic judgments may be based on the mutual interdependence between probabilities and values (see footnotes 3 and 5 on the previous page).

14. Belief in internal/external control could be measured by asking subjects to indicate on a scale how far future outcomes are believed to be controlled by oneself (own abilities) or by extemal

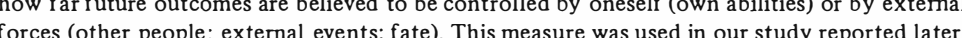
The formulation for the measure used in the study to be reported later was worked out by $\mathrm{H}$ Eckel and R.-W. Schmidt (diplom thesis, Universität Mannheim 1973).

15. The term optimism and pessimism is not used to indicate non-realistic judgment, unless stated in the present and what his actual outcomes will be in the future.

16. The diplom thesis of H. Eckel and R. W. Schmidt was based on this investigation.

17. Randomly selected persons: 100 adolescents of each sex between 14 and 16 years and 100 adults of both sexes between 35 and 45 years. In each age group half of the subjects were low and half were high status person. Thus for ench independent variable (status, sex, aes) there were two levels.

18. Social status was measured by educational level. Several studies have shown that level of edusignificantly with income and social status (Daheim 1970).

19. All differences reported here are at $\mathrm{p}<.05$ or below and have been obtained by analysis of variance (social status, age, sex

20. The concerns were categorized by two independent raters into several private and public categories. The total number of different categories was computed for each subject. (Private life: family, job, personal satisfaction; public life: economy, political and social development).

21. Extension was measured as the distance between subjects' actual age and the age at which the subjects thought the future event would occur. Only the most distant event was used for this measure.

22. Here: A greater variety of future-related concerns (number of different categories of concerns).

23. The person indicates on an eleven-point scale, where he stands on the ladder today (present), where he has stood in the past, and where he thinks he will stand in the future. The top of the "ladder of life" is the best possible life as defined by the person, and the bottom is the wors possible life, again, as defined by him (see Cantril 1965, p. 22).

Judgments were made for the total of the hopes and fears named by the subject; a list of ten areas of private concern (e.g., health, interpersonal relations) and ten areas of public concer (e.g., peace in the world, crise in the Federal Republic of Gerts 
BIBLIOGRAPHY

Abelson, R.P.; Aronson, E.; McGuire, W.J.; Newcomb, Th.M.; Rosenberg, M.J. and Tannenbaum, P.H. (Eds.): Theories of Cognitive Consistency: A Sourcebook. Chicago: Rand McNally 1968.

Barabasz, A.F.: "Temporal Orientation and Academic Achievement in College." Journal of Social Psychology, 80 (1970), 231-2.

Cantril, H.: The Pattern of Human Concerns. New Brunswick, N.J.: Rutgers University Press $\cdot 1965$.

Crandall, V.J.; Solomon, D. and Kellaway, R.: "Expectancy Statements and Decision Times as Functions of Objective Probabilities and Reinforcement Values." Journal of Personality, 24 (1955), 192-203.

Daheím, H.: "Soziale Herkunft, Schule und Rekrutierung der Berufe." Kölner Zeitschrift für Soziologie und Sozialpsychologie, Sonderheft 5 (1970), 200-17.

Doob, L.W.: Patterning of Time. New Haven: Yale University Press 1971.

Edwards, w.: "Utility, Subjective Probability; their Interaction and Variance Preferences." Joumal of Conflict Resolution, 6 (1962), 42-51.

Ellis, L.M.;Ellis, R.; Mandel, E.D.; Schaeffer, M.S.; Sommer, G. and Sommer, G.: "Time Orientation and Social Class. An Experimental Supplement." Journal of Abnormal and Social Psychology. 51 (1955), 146-7.

Feather, N.T.: "Subjective Probability and Decision under Uncertainty." Psychological Review, 66 (1959), 150-64.

Fröhlich, W.D.: "Sozialisation und kognitive Stile. Einige Denkmöglichkeiten und Befunde." In C.F. Graumann (Ed.), Handbuch der Psychologie, Vol. 7, p. 2. Gottingen: Hogref

Galtung, J.: "Images of the World in the Year 2000. A Synthesis of the Marginals of a Ten Nations-Study." European Coordination Centre for Research and Documentation in Social Science. Wien 1970.

Gore, P.M. and Rotter, J.B.: "A Personality Correlate of Social Action." Journal of Personality, 31 (1963), 58-64

Heckhausen, H.: The Anatomy of Achievement Motivation. New York: Academic Press 1967. Insko, Ch.A. and Schopler, J.: Experimental Social Psychology. New York: Academic Press 1972
Irwin, F.W.: "Stated Expectations as Functions of Probability and Desirability of Outcomes." Journal of Personality, 21 (1953), 329-35.

Judson, A.J. and Tuttle, C.E.: "Time Perspective and Social Class." Perceptual and Motor Skills, 23 (1966), 1074.

Kagan, J. and Kogan, N.: "Individual Variation in Cognitive Processes." in P.H. Mussen (Ed.), Carmichael's Manual of Child Psychology. Vol. 1. New York: John Wiley \& Sons 1970.

Kastenbaum, R.: "The Dimensions of Future Time Perspective. An Experimental Analysis." Journal of General Psychology, 65 (1961), 203-18.

Knapp, R.H. and GarbuttJ.T.: "Variations in Time Description and Need Achievement." Journal of Social Psychology, 67 (1965), 269-72.

Kogan, N. and Wallach, M.A.: "Risk taking as a Function of the Situation, the Person and the Group." In G. Mandler, P. Mussen, N. Kogan and M.A. Wallach (Eds.), New Directions in Psychology III. New York: Holt, Rinehart \& Winston 1967.

Lehr, U.: "Zur Problematik des Menschen im reiferen Erwachsenenalter - eine sozialpsychologische Interpretation der 'Wechseljahre'." In H. Thomae and U. Lehr (Eds.), Altern, Probleme und Tatsachen. Frankfurt/M: Akademische Verlags-gesellschaft 1968.

LeShan, L.L.: "Time Orientation and Social Class." Journal of Abnormal and Social Psycho$\log y, 47$ (1952), 589-92.

Lessing, E.E.: "Demographic, Developmental and Personality Correlates of Length of Future Time Perspective." Journal of Personality, 36 (1968), 183-201.

Maccoby, E.E. (Ed.): The Development of Sex Differences. Stanford: Stanford University Press 1966

McGuire, W.J.: "Theory of the Structure of Human Thought." In R.P. Abelson et al (Eds.) Theories of Cognitive Consistency: A Sourcebook. Chicago: Rand McNally 1968.

Mischel, W.: "Theory and Research" on the Antecedents of Self-imposed Delay of Reward." In B.A. Maher (Ed.), Progress in Experimental Personality Research. Vol. 3. New York: Academic Press 1966.

"Processes in Delay of Gratification." In L. Berkowitz (Ed), Advances in Experimental Social Psychology. Vol. 7. New York: Academic Press 1974.

Myrdal, A. and Klein, V.: Women's Two Roles: Home and Work. London: Routlege \& Kegan

Oevermann, U.: Sprache und soziale Herkunft. Frankfurt: Suhrkamp 1969.

Popitz, H.: Prozesse der Machtbildung. Tübingen: Paul Mohr 1968.

Rotter, J.B.: "Generalized. Expectancies for Internal versus External Control of Reinforcement." Psychological Monographs, 80 (1966), (1, Whole No. 609). 
Schneider, L. and Lysgaard. S.: "The Deferred Gratification Pattem: a Preliminary Study." American Sociological Review, $1 દ$ (1953), 143-49.

Streufert, S.: "Complexity and Complex Decision Making." Journal of Experimental Social Psychology, 6 (1970), 494-509.

: Teahan, J.E.: "Future Time Perspective, Optimism and Academic Achievement." Journal of Abnormal and Social Psychology, 57 (1958), 379-80.

Trommsdorff, G.: "Kommunikationsstrategie, sechs westdeutscher Frauenzeitschriften: Einkommenshöhe der Leserin als beschränkender Einfluss auf ihre sozialen Orientierungsmöglichkeiten." Kölner Zeitschrift für Soziologie und Sozialpsychologie, 1 (1969), 60-92.

Vaughn, J.A. and Knapp, R.H.: "A Study in Pessimism." Journal of Social Psychology, 59 (1963), 77-92

Wallace, M: "Future Time Perspective in Schizophrenia." Journal of Abnormal and Social Psy chology, 52 (1956), 240-45.

Weiner, B.: "New Conceptions in the Study of Achievement Motivation." In B.A. Maher (Ed.), Progress in Experimental Personality Research. Vol. S. New York: Academic Press 1970 